\title{
A COMPUTATIONAL FLUID DYNAMICS ANALYSIS OF SINGLE AND THREE NOZZLES MINIMUM QUANTITY LUBRICANT FLOW FOR MILLING
}

\author{
M.S. Najiha ${ }^{1}$ and M.M. Rahman ${ }^{1,2}$ \\ ${ }^{1}$ Automotive Engineering Research Group, Faculty of Mechanical Engineering \\ Universiti Malaysia Pahang, 26600 Pekan, Pahang, Malaysia \\ Email: mustafizur@ump.edu.my \\ Phone: +6094262239; Fax: +6094246222 \\ ${ }^{2}$ Automotive Engineering Centre, Universiti Malaysia Pahang, \\ 26600 Pekan, Pahang, Malaysia
}

\begin{abstract}
A 3-dimensional computational fluid dynamics analysis of minimum quantity lubricant flow for a four-tooth milling cutter operation with single and three nozzles is presented in this paper. CFD modelling is utilized to simulate the flow distribution around a fourtooth milling. The domain of a rotating cutter along with the spraying nozzle was defined. Operating cutting and boundary conditions were defined based on previous literature. A steady-state, pressure-based, planar analysis was performed with a viscous, realizable $\mathrm{k}-\varepsilon$ model. A 3-D transient-case, incompressible analysis for the minimum quantity lubricant is also performed. The domain of the milling cutter is rotated at a very high spindle speed, and a single nozzle is used to investigate the effects of MQL spray. A mixture of oils and air is sprayed onto the tool. Another analysis is performed with three nozzles placed at equal angles to each other around the periphery of the tool. A 2dimensional steady-state analysis is also carried out using CFD. The obtained results verify that the single nozzle cannot fully lubricate the rotating tool. It was observed that flow penetration into the cutting zone is dependent on the flow velocity and the number of nozzles. Hence, it can be concluded that the MQL nozzle arrangement can be improved with three nozzles with a constant mass flow rate.
\end{abstract}

Keywords: CFD; milling; MQL; nozzles; flow fields; vector plot.

\section{INTRODUCTION}

Minimum Quantity Lubrication (MQL) has been demonstrated to be an effective neardry machining technique as well as an efficient alternative to complete dry and wet cutting conditions from the viewpoint of cost, ecological and human health issues and machining process performance. MQL is a sustainable manufacturing technique that is safe for the environment, the worker and is cost-effective [1].The cost of cutting lubricants may range from 7 to $17 \%$ of the total machining cost [2], while the tool cost ranges from 2 to $4 \%$ [3-6]. Therefore minimization of metal working fluids can serve as a direct indicator of sustainable manufacturing. The goal of MQL is to machine parts using a minimal amount of metal working fluid, typically at a flow rate of $50-500 \mathrm{ml} / \mathrm{h}$, which is about three to four orders of magnitude lower than the amount commonly used in the flood cooling condition [7-11] so that the workpiece, chips and environment remain dry after cutting. The concept of minimum quantity lubrication, sometimes 
referred to as near-dry lubrication [12] or microlubrication [13], was suggested a decade ago as a means of addressing the issues of environmental intrusiveness and occupational hazards associated with the airborne cutting fluid particles on factory shop floors. In the recent past, there has been a general liking for dry machining [14-18]. On the other hand, several researchers have started exploring the application of minimal cutting fluid. Minimum quantity lubrication offers considerable advantages over the conventional traditional wet machining processes, as well as dry machining. The machined parts are lubricated with a very small amount of fluid sprayed on them, resulting in a very low residue of lubricant on the chips, tool and workpiece, hence their cleaning is easier and cheap; recycling of chips is easy as is scrutiny of the machining process, since the machining area is not flooded. Machining with MQL has been extensively applied in many machining processes such as drilling [19-22], milling [23-29], turning [8, 21, 3032], and MQL grinding [33-35]. MQL is contributing significantly towards performance and quality in the environment, working condition and economics of machining. Since it does not require the power-consuming auxiliary equipment like compressors, pumps and chillers that are used in a flooded lubricating system, it significantly reduces energy consumption. With MQL, when properly applied, both parts and chips remain dry and are easier to handle [36]. It therefore makes recycling of the metal chips easier. MQL is an achievement-oriented technology, which replaces the conventional lubrication techniques and takes over the lubrication task, assisting in sustainable development with mechanical manufacturing processes. Most of the research conducted with respect to minimum quantity lubrication and related issues is related to showing the overall advantages of MQL as opposed to the use of a conventional emulsion coolant, and there have been several successful experiences when it is used in the machining of different materials.

Dry machining has always been associated with the traditional manufacturing processes, but the current surge in interest in dry machining is due to the growing global realization of the cost of cutting fluids management. Dry machining is described as an ideal replacement to the traditional conventional flooded cooling, and lubricating machining practices. However, one of the major obstacles in adopting dry machining is the belief of the machinists that no-fluid cutting may lead to a poor surface finish and dimensional inaccuracies. The most prohibitive part of switching towards dry machining is the initial capital expenditure associated with special expensive tooling, and nonretrofitting machines. Research on dry machining has been mainly concerned with the development of appropriate tools and coatings [12, 26, 37-41]. Although dry machining is possible in some situations, there are still several issues regarding lubricity, tool life, thermal damage of the workpiece, etc. [21, 36, 42]. In this context, MQL techniques have been proposed. Conventional wet machining requires pumping millions of gallons of metal-working fluids to cool and lubricate cutting tools and remove the metal chips from the machines. These fluids, typically a mixture of coolant and water, must be regularly treated to control their chemical composition, and they require special disposal to avoid contaminating the environment. Wet machining systems also require a large system of pipes, pumps, filters and tanks to circulate and store the fluids. MQL delivers significant benefits in environmental performance, quality, working condition and costs. It significantly reduces energy consumption, because it does not require the energyconsuming auxiliary machines like compressors, pumps and chillers used in a wet system. MQL also makes it easier to recycle the metal chips created during the machining process. Machining with a minimum quantity of lubricant is a greater opportunity for the world to manufacture new products for better overall performance 
with lower emissions, reduced risk and compliance with the regulations. Another characteristic of this technology is that when properly applied, both parts and chips remain dry and are easier to handle [36]. Most of the research conducted with respect to minimum quantity lubrication and related issues is related to showing the overall advantages of MQL as opposed to the use of a conventional emulsion coolant, and there are several successful experiences when it is used in the machining of different materials. This study presents the effect of the number of nozzles on MQL flow in the milling process. The analysis of the spray nozzle flow is studied in the domain of a rotating cutter. A three-dimensional CFD study will be performed to investigate the spraying of an oil-compressed air mixture onto the cutting zone with one nozzle placed at some angle with the tool feed direction. The nozzle distance and height from the cutting points are also included in the study. Factors studied include correct penetration of the MQL jet into the cutting zone and the relative position between the nozzle and tool. Three nozzles are placed equidistant from the cutting zone at equal angles.

\section{METHODS AND MATERIALS}

A milling cutter with four teeth is used as the model rotating at $2000 \mathrm{rpm}$. The cutting medium is assumed to be a mixture of compressed air and oil. The mixture properties are presented in Table 1. The mass-fraction of the oil is assumed constant throughout the compressed air. The three-dimensional model and steady-state, pressure-based, 2-D and $3-D$ analyses were performed utilizing the ANSYS Fluent solver. The viscous, realizable $\mathrm{k}-\varepsilon$ model is used. A pressure-velocity coupled scheme is used with 200 courant number. The diameter of the nozzle is considered to be $2 \mathrm{~mm}$. In the case of 3-D analysis, the nozzle is placed at $45^{\circ}$ to the tool axis of rotation and at a height of $15 \mathrm{~mm}$ and $15 \mathrm{~mm}$ from the cutter-workpiece interface. The density of the air-oil mixture is taken as the weighted average of the air and oil densities. An unstructured mesh with tetragonal elements is used with a maximum edge length of $0.006 \mathrm{~mm}$ and minimum edge length of $0.00002714 \mathrm{~mm}$. The three-dimensional meshed domain is shown in Figure 1. The nozzle is modelled for balanced mass flow rate within the domain. Smaller mesh sizes are selected for the geometry close to the tool and workpiece interface region, i.e. in the cutting zone, to obtain more accurate results. In the case of 2-D analysis for three nozzles, the nozzles are placed $120^{\circ}$ apart. An equal flow rate is assumed from every nozzle. The two-dimensional meshed domain is shown in Figure 2.

Table 1. Mixture properties.

\begin{tabular}{lc}
\hline \multicolumn{1}{c}{ Description } & Value \\
\hline Compressed air pressure $(\mathrm{MPa})$ & 0.4 \\
Air viscosity $(\mathrm{kg} / \mathrm{m}-\mathrm{s})$ & $1.7894 \times 10^{-5}$ \\
Air density $\left(\mathrm{kg} / \mathrm{m}^{3}\right)$ & 1.225 \\
Air volume flow rate (litre $/ \mathrm{min})$ & 72.6 \\
Compressed air inlet velocity $(\mathrm{m} / \mathrm{s})$ & 231 \\
Oil viscosity $(\mathrm{kg} / \mathrm{m}-\mathrm{s})$ & $88 \times 10^{-4}$ \\
Density of oil $\left(\mathrm{kg} / \mathrm{m}^{3}\right)$ & $0.96 \times 10^{3}$ \\
Specific heat of oil $(\mathrm{J} / \mathrm{kg})$ & 2.0 \\
Thermal conductivity of oil $(\mathrm{W} / \mathrm{Mk})$ & 231 \\
Oil volume flow rate $(\mathrm{ml} / \mathrm{hr})$ & 15 \\
\hline
\end{tabular}




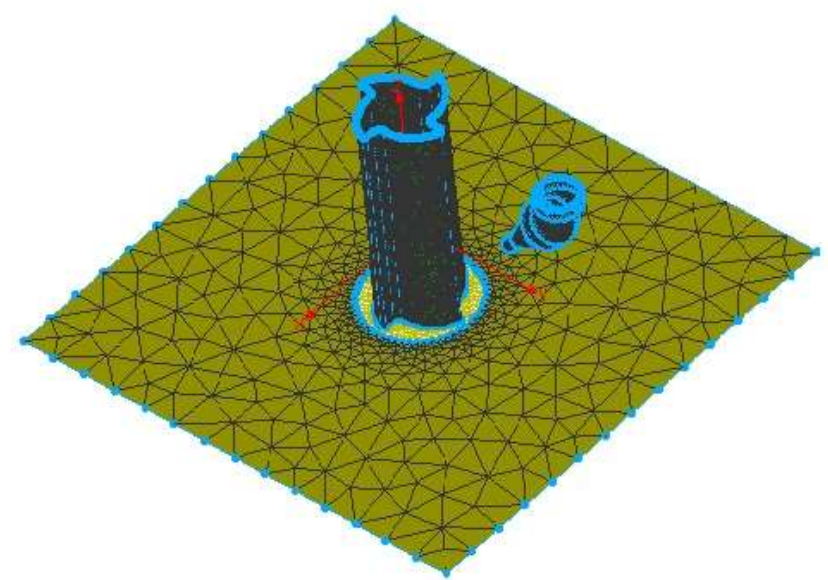

Figure 1. Two-dimensional meshed domains of single-nozzle MQL system.

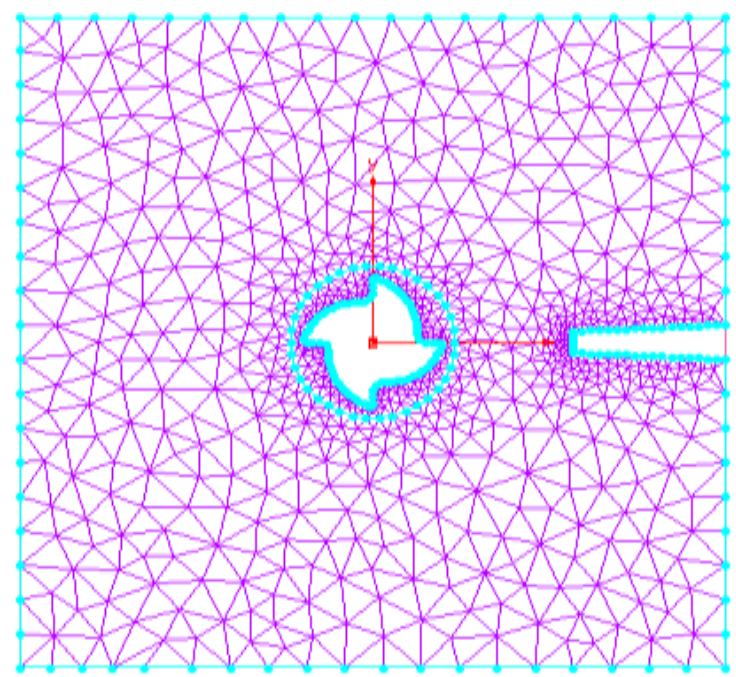

(a) Single nozzle

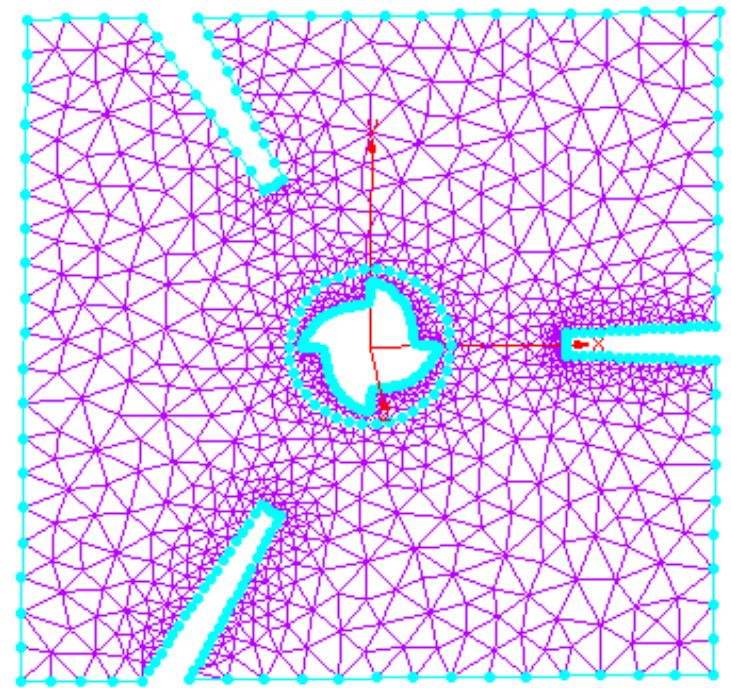

(b) Three nozzles

Figure 2. Two-dimensional meshed domain for single- and three-nozzle MQL system. 


\section{RESULTS AND DISCUSSION}

The effects of minimum quantity lubricant flow are examined on a rotating end mill. The study is done to investigate the effects of nozzles in the spraying of a minimum quantity of lubricant onto the tool-workpiece interface. Figure 3 shows the velocity contour for the tool and path lines for the MQL jet in the case of three-dimensional single-nozzle analysis. The velocity vector plot for the MQL jet shows that the spray does not cover the periphery of the tool. The observation is in conformance with the results obtained in a previous study. The cutting surface is not entirely lubricated. The flow is scattered because of the high vortex created by the high speed of the cutter. The flow strikes the cutter but splashes back because of the turbulence.

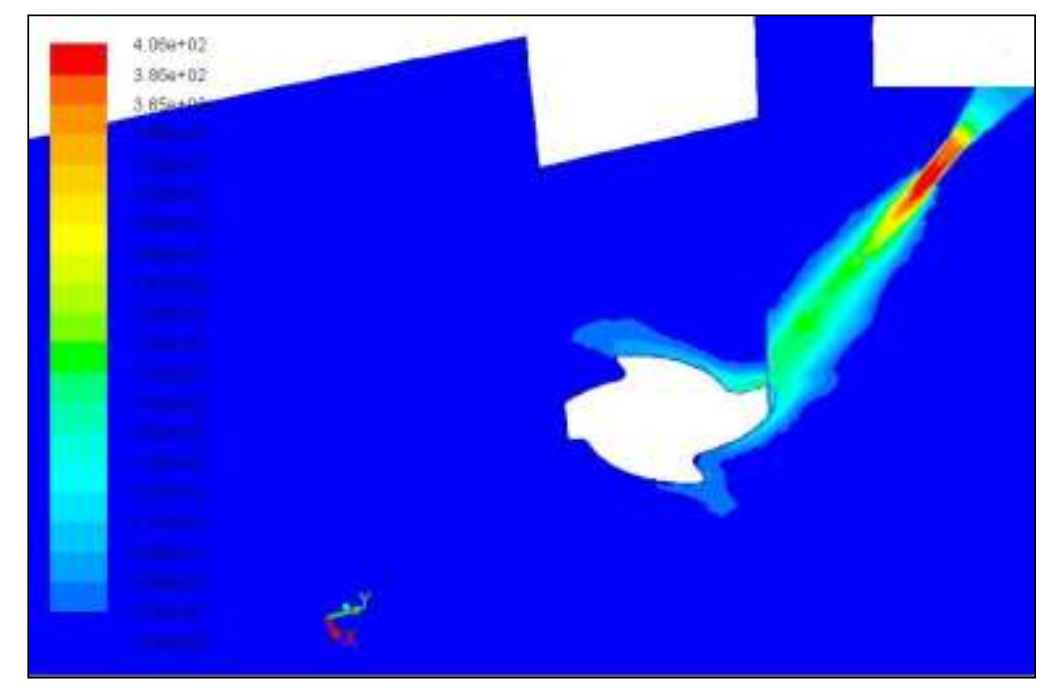

(a) Velocity contours

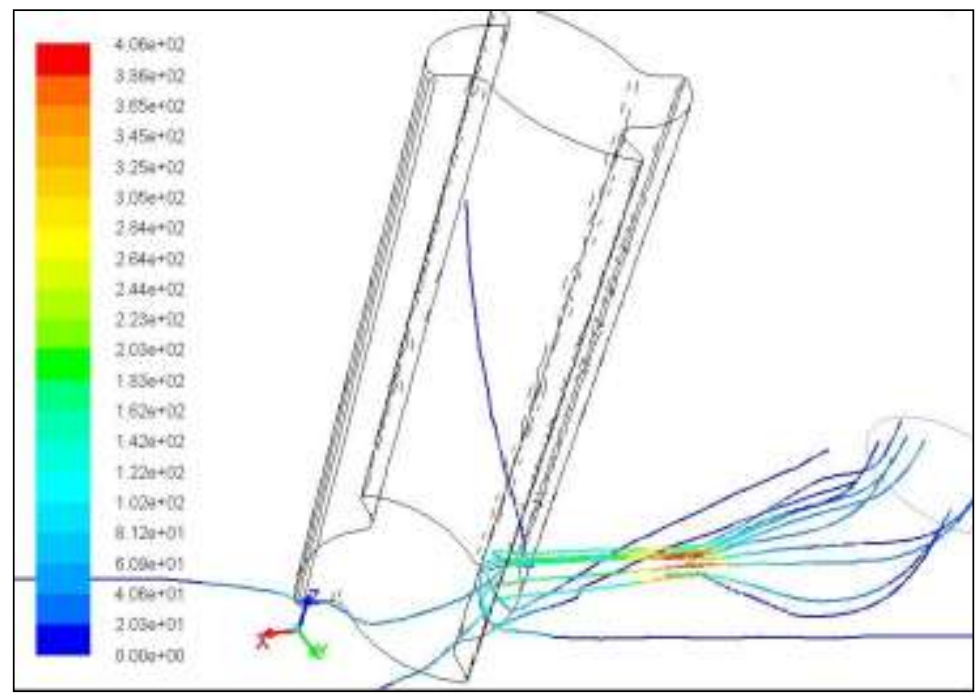

(b) Path lines

Figure 3. Velocity contours and path lines for the jet of single-nozzle MQL system. 
The fluid flow rate is not sufficient to penetrate into the cutting zone. This is in conformance with the results and observations obtained from the 2-D single-nozzle analysis. It is observed that the fluid flow rate has to be increased in order to ensure that the fluid penetrates into the cutting zone. The problem of incomplete lubrication, i.e., uneven distribution of the fluid along the periphery of the tool, can be solved by using more than the single nozzle. The nozzle position in relation to feed direction is very important in order to obtain the optimum effect of the MQL flow. In the case of 3-D analysis, the position of the nozzle (nozzle height and axial distance) produces some improvement in the distribution of the fluid compared to the results obtained from 2-D analysis.

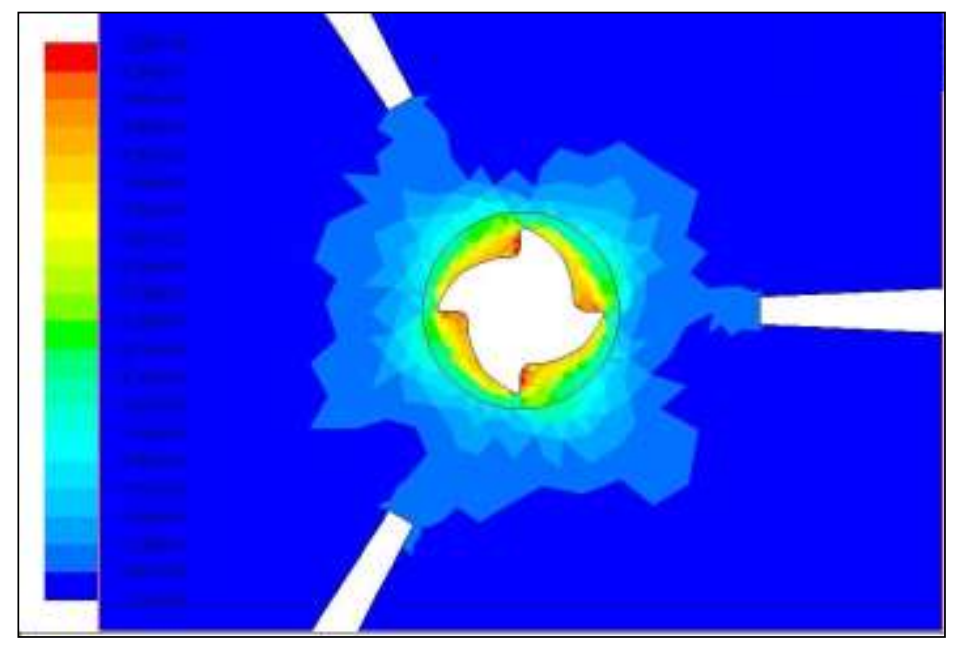

(a) Velocity contours

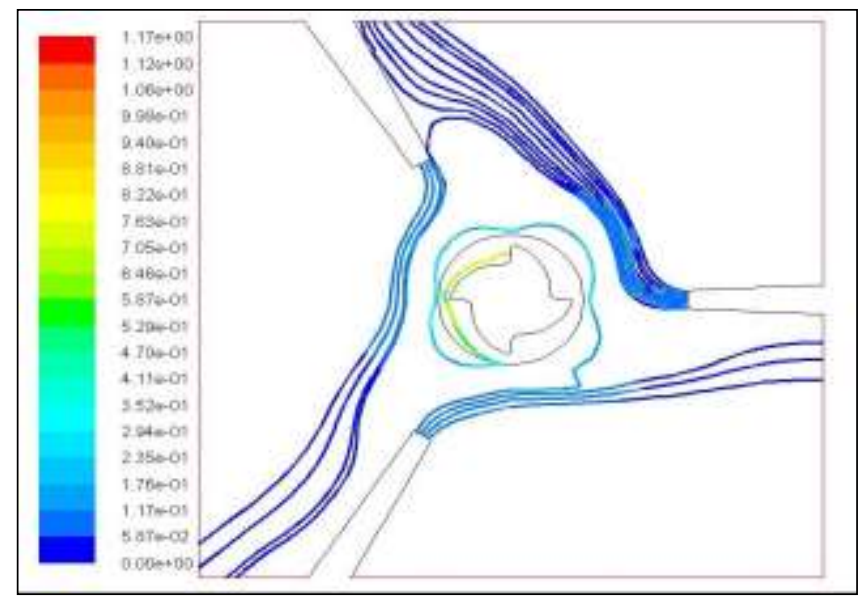

(b) Path lines

Figure 4. Velocity contours and path lines for the jet of three nozzles MQL system.

A steady-state, pressure-based 2-dimensional analysis is performed. The mass fraction of the oil is assumed constant throughout the compressed air. Three nozzles are used instead of the single nozzle. The nozzles are placed at $120^{\circ}$ to each other. Figure 4 shows the velocity contour of the flow field and path lines of the MQL jet in the case of the three-nozzle analysis. The flow field shows that spray from the three nozzles, 
equidistant from each other, covers the periphery of the tool. A turbulence region is created around the rotating tool as it is rotating at a very high speed. This turbulent region prevents the penetration of the fluid into the cutting zone.

\section{CONCLUSIONS}

The CFD analysis of the arrangement of the nozzles around the tool periphery is performed in order to study the effect of the MQL jet and number of nozzles on the lubrication region. It was observed that flow penetration into the cutting zone is dependent on the flow velocity and the number of nozzles. A single nozzle with a very small flow velocity cannot achieve complete lubrication using MQL fluid. A threedimensional analysis is performed in order to verify the results and observations from the 2-dimensional study. The results show that the nozzle height and distance from the cutting zone play a vital role in the analysis. The 3-dimensional analysis shows that a single nozzle is not sufficient for complete lubrication of the rotating tool in MQL. The three nozzles may work well for the complete lubrication of the rotating tool. Three nozzles placed at equal angles to each other and equidistant from the tool are modelled, and the MQL flow pattern is analysed using steady-state planar assumptions. Hence it can be concluded that the most effective MQL nozzle performance is with the threenozzle arrangement keeping the mass flow rate constant.

\section{ACKNOWLEDGMENTS}

The researcher would like to thank the Faculty of Mechanical Engineering, Universiti Malaysia Pahang for providing laboratory facilities and financial support under project no. RDU110110 and Graduate Research Scheme (No. GRS140310).

\section{REFERENCES}

[1] Marksberry PW, Jawahir IS. A comprehensive tool-wear/tool-life performance model in the evaluation of NDM (near dry machining) for sustainable manufacturing. . International Journal of Machine Tools and Manufacture. 2008;48:878-86.

[2] Weinert K, Inasaki I, Sutherland JW, Wakabayashi T. Dry machining and minimum quantity lubrication. CIRP Annals - Manufacturing Technology. 2004;53:511-37.

[3] Attanasio A, Gelfi M, Giardini C, Remino C. Minimal quantity lubrication in turning: effect on tool wear. Wear. 2006;260:333-8.

[4] Najiha MS, Rahman MM, Yusoff AR, Kadirgama K. Investigation of flow behavior in minimum quantity lubrication nozzle for end milling processes. International Journal of Automotive and Mechanical Engineering. 2012;6:76876.

[5] Puvanesan M, Rahman MM, Najiha MS, Kadirgama K. Experimental investigation of minimum quantity lubrication on tool wear in aluminum alloy 6061-t6 using different cutting tools. International Journal of Automotive and Mechanical Engineering. 2014;9:1538-49.

[6] Najiha MS, Rahman MM, Kamal M, Yusoff AR, Kadirgama K. Minimum quantity lubricant flow analysis in end milling processes: A computational fluid 
dynamics approach. Journal of Mechanical Engineering and Sciences. 2012;3:340-5.

[7] Thakur DG, Ramamoorthy B, Vijayaraghavan L. Optimization of minimum quantity lubrication parameters in high speed turning of superalloy Inconel 718 for sustainable development. World Academy of Science, Engineering and Technology. 2009;54,224-6.

[8] Autret R, . SYL. Minimum quantity lubrication in finish hard turning. International Conference on Humanoid, Nanotechnology, Information Technology, Communications and Control, Environment and Management HNICEM '032003.

[9] Dhar NR, Kamruzzaman M, Ahmed M. Effect of minimum quantity lubrication (MQL) on tool wear and surface roughness in turning AISI-4340 steel. Journal of Materials Processing Technology. 2006;172.

[10] Khan MAR, Rahman MM, Kadirgama K, Maleque MA, Ishak M. Prediction of surface roughness of Ti-6Al-4V in electrical discharge machining: A regression model. Journal of Mechanical Engineering and Sciences. 2011;1:16-24.

[11] Yusoff AR, Mohamed Suffian MRZ, Taib MY. Literature review of optimization technique for chatter suppression in machining. Journal of Mechanical Engineering and Sciences. 2011;1:47-61.

[12] Klocke F, Eisenblatter G. Dry cutting. Annals of CIRP 1997;46:519-26.

[13] MaClure TF, Adams R, Gugger MD. Comparison of flood vs. microlubrication on machining performance. http://wwwunistcom/ techsolvehtml. 2007.

[14] Sreejith PS, Ngoi BKA. Dry machining: machining of the future. Journal of Material Processing Technology. 2000; 101:287-91.

[15] Khan MAR, Rahman MM, Kadirgama K. Electrode wear rate of graphite electrodes during electrical discharge machining processes on titanium alloy $\mathrm{Ti}$ 5Al-2.5Sn. International Journal of Automotive and Mechanical Engineering. 2014;9:1782-92.

[16] Kumar S, Singh R. Investigation of surface properties in manganese powder mixed electrical discharge machining of OHNS and D2 die steels. International Journal of Automotive and Mechanical Engineering. 2010;2: 181-99.

[17] Singh R. Comparison of statistically controlled machining solutions of titanium alloys using USM. International Journal of Automotive and Mechanical Engineering. 2010;1:66-78.

[18] Singh R, Singh B. Comparison of cryo-treatment effect on machining characteristics of titanium in electric discharge machining. International Journal of Automotive and Mechanical Engineering. 2011;3:239-48.

[19] Braga DU, Diniz AE, Miranda GWA, Coppini NL. Using a minimum quantity of lubricant (MQL) and a diamond coated tool in the drilling of aluminumsilicon alloys. Journal of Materials Processing Technology. 2002;122:127-38.

[20] Filipovic A, Stephenson DA. Minimum quantity lubrication applications in automotive power-train machining. Machining Science and Technology. 2006;10:3-22.

[21] Davim JP, Sreejith PS, Silva J. Turning of brasses using minimum quantity of lubricant and flooded lubricant conditions. Materials and Manufacturing Processes. 2007;22:45-50.

[22] Heinemann R, Hinduja S, Barrow G, Petuelli G. Effect of MQL on the tool life of small twist drills in deep-hole drilling. International Journal of Machine Tools and Manufacture. 2006;46:1-6. 
[23] Rahman M, Kumar AS, Salam MU. Experimental evaluation on the effect of minimal quantities of lubricant in milling. International Journal of Machine Tools and Manufacture. 2002;42:539-47.

[24] Rahman M, Kumar AS, Salam MU. Evaluation of minimal quantities of lubricant in end milling. International Journal of Advanced Manufacturing Technology. 2001;18:235-41.

[25] Lacalle LNLD, Angulo C, Lamikiz A, Sanchez JA. Experimental and numerical investigation of the effect of spray cutting fluids in high speed milling. Journal of Materials Processing Technology. 2006;172:11-5.

[26] Su YL, Liu TH, Su CT, Yao SH, Kao WH, Cheng KW. Wear of CrC-coated carbide tools in dry machining. Journal of Materials Processing Technology. 2006;171:108-17.

[27] Liao YS, Lin HM. Mechanism of minimum quantity lubrication in high speed milling of hardened steel. International Journal of Machine Tools and Manufacture. 2007;47:1660-6.

[28] Rahman MM, Kadirgama K, Ab Aziz AS. Artificial neural network modeling of grinding of ductile cast iron using water based $\mathrm{SiO} 2$ nanocoolant. International Journal of Automotive and Mechanical Engineering. 2014;9:1649-61.

[29] Razak NH, Rahman MM, Kadirgama K. Experimental study on surface integrity in end milling of hastelloy C-2000 superalloy. International Journal of Automotive and Mechanical Engineering. 2014;9:1578-87.

[30] Wakabayashi T, Sato H, Inasaki I. Turning using extremely small amounts of cutting fluids. JSME International Journal. 1998;41:143-8.

[31] Dhar NR, Kamruzzaman M, Mahiuddin A. Effect of minimum quantity lubrication (MQL) on tool wear and surface roughness in turning AISI-4340 steel. Journal of Materials Processing Technology. 2006;172:299-304.

[32] Kamata Y, Obikawa T. High speed MQL finish-turning of Inconel 718 with different coated tools. Journalof Material Processing Technology. 2007;192:2816.

[33] Baheti U, Guo C, Malkin S. Environmentally conscious cooling and lubrication for grinding. In: Performance PotISoIMT, editor.1998. p. 643-54.

[34] Hafenbraedl D, Malkin S. Environmentally-conscious minimum quantity lubrication (MQL) for internal cylindrical grinding. Transactions of North American Manufacturing Research Institution/Society of Manufacturing Engineers (NAMRI/SME)2000. p. 149-54.

[35] Silva LR, Bianchi EC, Catai RE, Fusse RY, Franca TV. Study on the behavior of the minimum quantity lubricant - MQL technique under different lubricating and cooling conditions when grinding ABNT 4340 steel. Journal of the Brazilian Society of Mechanical Sciences and Engineering 2005;27:192-9.

[36] Itoigawa F, Childs THC, Nakamura T, Belluco W. Effects and mechanisms in minimal quantity lubrication machining of an aluminum alloy. Wear. 2006;260:339-44.

[37] Shen $\mathrm{CH}$. The importance of diamond coated tools for agile manufacturing and dry machining. Surface and Coating Technology. 1996;86-87:672-7.

[38] Machado AR, Wallbank J. The effect of extremely low lubricant volumes in machining. Wear. 1997;210:76-82.

[39] Nouari M, List G, Girot F, Coupard D. Experimental analysis and optimisation of tool wear in dry machining of aluminium alloys. Wear. 2003;255:1359-68. 
[40] Kobayashi S, Ohgoe Y, Ozeki K, Sato K, Sumiya T, Hirakuri KK, et al. Diamond-like carbon coatings on orthodontic archwire. Diamond and Related Materials. 2005;14:1094-7.

[41] Reddy NSK, Rao PV. Selection of an optimal parametric combination for achieving better surface finish in dry milling using genetic algorithms. International Journal of Advanced Manufacturing Technology. 2006;28:463-73.

[42] Sun J, Wong YS, Rahman M, Wang ZG, Neo KS, Tan CH, et al. Effects of coolant supply methods and cutting conditions on tool life in end milling titanium alloy. Machining Science and Technology. 2006;10:355-70. 